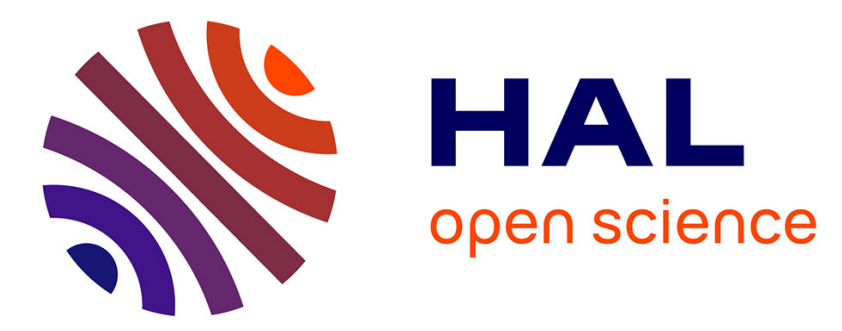

\title{
Detonation peninsula for TRF-air mixtures: assessment for the analysis of auto-ignition events in spark-ignition engines
}

\author{
Ahmed Guerouani, Anthony Robert, Jean-Marc Zaccardi
}

\section{- To cite this version:}

Ahmed Guerouani, Anthony Robert, Jean-Marc Zaccardi. Detonation peninsula for TRF-air mixtures: assessment for the analysis of auto-ignition events in spark-ignition engines. SAE International Journal of Engines, 2018, SAE Technical Paper 2018-01-1721. 10.1177/1468087417712160 . hal-01978654

\section{HAL Id: hal-01978654 \\ https://hal-ifp.archives-ouvertes.fr/hal-01978654}

Submitted on 11 Jan 2019

HAL is a multi-disciplinary open access archive for the deposit and dissemination of scientific research documents, whether they are published or not. The documents may come from teaching and research institutions in France or abroad, or from public or private research centers.
L'archive ouverte pluridisciplinaire HAL, est destinée au dépôt et à la diffusion de documents scientifiques de niveau recherche, publiés ou non, émanant des établissements d'enseignement et de recherche français ou étrangers, des laboratoires publics ou privés. 


\section{Detonation peninsula for TRF-air mixtures: assessment for the analysis of auto-ignition events in spark-ignition engines}

\begin{abstract}
Controlling abnormal auto-ignition processes in spark-ignition engines requires understanding how auto-ignition is triggered and how it propagates inside the combustion chamber. The original Zeldovich theory regarding auto-ignition propagation was further developed by Bradley and coworkers, who highlighted different modes by considering various hot spot characteristics and thermodynamic conditions around them. Dimensionless parameters $(\varepsilon, \xi)$ were then proposed to classify these modes and to define a detonation peninsula for $\mathrm{H}_{2}-\mathrm{CO}$-air mixtures.
\end{abstract}

This article deals with numerical simulations undertaken to check the relevancy of this original detonation peninsula when considering realistic gasoline fuels. 1D calculations of auto-ignition propagation are performed using the Tabulated Kinetics for Ignition model. Chemical kinetics calculations are first carried out to build the needed look-up table for the auto-ignition delay time $\tau_{\mathrm{i}}$, and the excitation times $\tau_{\mathrm{e}}$ of E10-air mixtures using a RON 95 TRF surrogate.

The dimensionless parameter $\varepsilon$ is based on the hot spot radius and on the excitation time $\tau_{\mathrm{e}}$ of the fuel. Previous chemical kinetics calculations confirm the impact of the fuel on this parameter as $\mathrm{H}_{2-}$ CO-air mixtures feature much longer excitation times than TRF-air mixtures. Focusing on the parameter $\xi$, its estimation depends on hot spots characteristics and thermodynamic conditions. The limits of the peninsula therefore vary depending on initial conditions and hot spot characteristics, that is why this paper focuses on several conditions to validate the dependency of the boundaries between the different autoignition modes. Hundreds of simulations are performed and due to the large amount of calculations, a specific post-processing methodology is defined to determine the auto-ignition propagation modes by automatically characterizing the coupling conditions between reaction and pressure waves. Several new detonation peninsulas are finally proposed depending on initial conditions in terms of temperature, pressure, fuel-air equivalence ratio and dilution. Limits of the detonation peninsula for TRF-air mixtures are more affected depending on each operating conditions. These new limits can finally be used to better understand abnormal auto-ignition events in spark-ignition engines.

\section{Introduction}

Two main abnormal combustions are observed in modern sparkignition engines: knock and low speed pre-ignition. Knock has been

Page 1 of 8 observed for the first time in 1882 by Sir Dugald Clerk who described it as a "persistent and troublesome enemy" [1] while the first observations of low-speed pre-ignition (LSPI) date back to the beginning of years 2000. However, in both cases, the triggering and the development of the abnormal combustion process rely on the auto-ignition characteristics of the air/fuel mixture.

In order to control these abnormal phenomena, it is necessary not only to better understand how and when an auto-ignition can be triggered by "hot spots", but also how it will propagate inside the combustion chamber since the auto-ignition intensity and the potential resulting engine damages are linked to both aspects. Different approaches such as the Livengood-Wu integral can be used to predict the auto-ignition temporal onset. However, advanced tools and methodologies are still being developed to better understand and predict the auto-ignition propagation modes.

The original theory regarding the auto-ignition propagation mode was provided by Zeldovich [2] who introduced three main modes by which the reaction front can propagate. The numerical analysis of these modes was then further explored by several groups of researchers, and is still the subject of new investigations. In the early 1990s, mathematical models were introduced for example by Goyal et al. [3] in order to simulate hot spot ignition in one dimensional geometries with $\mathrm{H} 2-\mathrm{O} 2$ mixtures and using a detailed mechanism for gas phase reaction. At that time, even mixtures featuring two hot spots could be simulated to study the interactions of two ignition processes as it can be the case in realistic engines conditions. The extension of these works in [4] showed that the transition from deflagration to detonation could also be simulated for $\mathrm{CH} 4$-air mixtures. A dual experimental and numerical analysis was also provided by König et al. [5]. 1D and 2D simulations were performed to take into account burned gases around the hot spot from the very beginning of auto-ignition. The overall theory was further developed by Bradley and co-workers at Leeds University to analyze autoignition processes during CAI combustion [6], during knocking combustion [7], and lately during LSPI [8]. Their auto-ignition calculations for $50 \% \mathrm{H}_{2}-50 \% \mathrm{CO}$-air mixtures allowed to highlight and to analyze the different propagation modes in various conditions. A specific classification diagram based on two dimensionless parameters has then been defined. Since then, this so-called "detonation peninsula" has been used for the analysis of both experimental occurrences of auto-ignition [9] and numerical results [10-11]. The recent studies of knocking combustion and LSPI require however to consider fuels whose auto-ignition characteristics are very different from those of $\mathrm{H}_{2}-\mathrm{CO}$. Results obtained with n-heptane-air 
and isooctane-air mixtures have been recently illustrated by Bates et al. [12] but not fully compared to the original results from $\mathrm{Gu}$ et al. [13]. More recently, Chen et al. have thoroughly analyzed several simulation results obtained with n-heptane-air mixtures, by considering non-uniform mixture compositions, or even cool spots within the Negative Temperature Coefficient (NTC) region [14]. These results have highlighted the different auto-ignition propagation modes but the characteristics of n-heptane-air mixtures have not been compared to those of $\mathrm{H}_{2}$-CO-air or TRF-air mixtures, and the detonation peninsula location has not been compared to that defined by $\mathrm{Gu}$ et al. [13].

This article aims at confirming the relevancy of the original detonation peninsula when considering realistic fuels used in modern gasoline engines based on similar simulations as those performed by Bradley et al.. The detonation peninsula position has already been discussed during the last Conference on Modeling and Diagnostics for Advanced Engine Systems (COMODIA, Okayama, July 2017) and then published in the International Journal of Engine Research [15] with only an initial condition for $P_{0}$ and $T_{0}$. This new study provides further analyses and presents the latest results of the authors.

The first section introduces the main features of the original theory allowing characterizing the auto-ignition propagation mode. The second section introduces the numerical procedure used to reproduce the different auto-ignition propagation modes. The third section focuses then on the main hypothesis involved in the estimation of the key parameters $\xi$ and $\varepsilon$, and shows that final peninsula location strongly depends on this assumption. Finally, different peninsulas are plotted looking at parametric variations as initial conditions in terms of $P_{0}, T_{0}$, equivalence ratio and dilution rate.

\section{Theoretical background}

Auto-ignition in Spark Ignition (SI) engines appears randomly in time during the engine cycle, after the spark in the case of knocking combustion, or after a first flame propagation phase in the case of LSPI. Regarding its location, auto-ignition is triggered in reactive centers resulting from mixture heterogeneities inside the combustion chamber. These heterogeneities are linked to higher temperatures, to the local mixture composition featuring an increased reactivity (local fuel/air and dilution ratios), or even to external perturbations like solid particles or oil droplets. It is usually assumed, however, that reactive auto-ignition centers correspond to temperature gradients within the mixture that is why these are often called "hot spots".

Two kinds of waves are generated when auto-ignition is triggered: a reaction wave associated with the chemical propagation of the reactive front and a pressure wave initiated by the thermal explosion of the hot spot at the very beginning of auto-ignition. If the local overpressure generated at the moment of auto-ignition is strong enough to provide a critically short auto-ignition delay time in the surrounding mixture, the reactive front and the pressure wave may couple and form a detonation wave, which propagates throughout the mixture. Both waves are intrinsically linked, since the compression of the mixture close to the hot spot contributes to an increase in reactivity and propagates auto-ignition.

Zeldovich [2] showed that a one-dimensional thermal hot spot characterized by its radius and by its temperature gradient between its center and the surrounding mixture lead to four kinds of auto-ignition propagation modes. The first case corresponds to a supersonic autoignition with a reaction wave propagating ahead of the pressure wave. In Zeldovich's classification thermal explosions represent a limit case of supersonic auto-ignition with an infinite propagation speed of the reactive front. The second one corresponds to the stationary detonation for which the shock wave compresses the unburned gas ahead of it, thereby supporting and reinforcing the chemical reaction. The pressure and the reaction waves have thus the same speed which is theoretically the Chapman-Jouguet speed. Both waves continuously interact and amplify each other, resulting in high local pressure levels. Finally, the third and the fourth modes concern subsonic auto-ignition propagations, one with the reaction wave faster than the laminar flame speed and the other with the reaction wave slower, so that normal flame propagation driven by the laminar flame speed occurs. The different flame propagation modes issued from auto-ignition are widely discussed in literature [6-14].

This original theory has then been further developed and applied to the analysis of auto-ignition in internal combustion engines by $\mathrm{D}$. Bradley and his co-workers at the University of Leeds [6-8,13]. A specific numerical methodology has been developed to determine the auto-ignition propagation mode around a one-dimensional thermal hot spot characterized by its radius $r_{0}$ and by its temperature gradient between its center and the surrounding mixture $\partial T / \partial r$. Two dimensionless parameters $(\varepsilon, \xi)$ were defined depending on the hot spot characteristics and on the surrounding fresh gas mixture properties (pressure, temperature, fuel/air equivalence ratio, dilution ratio).

$\xi$ describes the coupling between the acoustic wave propagating at the speed of sound $a$, and the reaction wave propagation at the speed $u_{a}$. It can be written as a dimensionless temperature gradient considering the temperature gradient between the center of the hot spot and the surrounding mixture, and the auto-ignition delay $\tau_{i}$ (Eq. $1)$.

$$
\text { Eq. } 1 \quad \xi=\frac{a}{u_{a}}=\frac{a}{\partial r / \partial \tau_{i}}=\frac{a}{\partial r / \partial T^{. \partial T} / \partial \tau_{i}}
$$

$\xi$ parameter is also written as a dimensionless temperature gradient by defining a critical hot spot temperature gradient (Eq. 2) for which the chemical resonance between the pressure wave and the reaction front occurs:

$$
\begin{aligned}
& \text { Eq. } 2 \quad \xi=(\partial T / \partial r) \cdot(\partial T / \partial r)_{c}^{-1} \\
& \text { with }(\partial T / \partial r)_{c}=a^{-1} \cdot\left(\partial \tau_{i} / \partial T\right)^{-1}
\end{aligned}
$$

Theoretically, detonation is achieved as soon as the reaction and pressure waves propagate at the same speed $(\xi=1,[16])$. However, because of species and thermal diffusion during the induction period, a developing detonation is not stringently restricted to this critical value $\xi=1$. In fact, depending on the reactivity, a wider range of initial conditions can lead to a developing detonation. Thus, an upper limit $\xi_{u}$ and a lower limit $\xi_{l}$ have been introduced to classify the different propagation modes and to define a so-called detonation peninsula.

The second dimensionless parameter $\varepsilon$ compares the characteristic chemical time scale given by the excitation time $\tau_{e}$, and the acoustic time scale given by $r_{0} / a$ (Eq. 3). By quantifying the rate at which the

Page 2 of 8 
auto-ignition chemical energy is released into the acoustic wave, $\varepsilon$ measures the hot spot reactivity.

$$
\text { Eq. } 3 \varepsilon=\frac{r_{0} / a}{\tau_{e}}
$$

It must be noted that $\varepsilon$ and $\xi$ are determined as a function of initial conditions (before chemical reactions start). Usually, characteristics of the fresh gas needed to determine $\xi$ and $\varepsilon$ are directly known (pressure, fuel/air ratio) or derived (temperature and dilution) from experimental data or simulations. The main issue is the estimation of the thermal hot spot properties (radius and temperature gradient). In academic cases like 1D simulations of this article, controlling these properties is easy. When considering real engine geometry and conditions, it is much more complex and hot spot properties need to be assumed especially in experiment. The estimation is still difficult using numerical simulations but not impossible looking at distributions of computed gradient and radius for example.

Lots of recent studies [17-20] used this detonation peninsula to analyze experimental and numerical occurrences of knock and LSPI in highly charged SI engines. It is therefore essential to validate the location of this peninsula for realistic gasoline fuel.

\section{Numerical set-up}

To analyze auto-ignition behavior, one dimensional calculations are performed using the AVBP compressible and reactive solver codeveloped by IFPEN and CERFACS [21]. The computational domain is presented in Figure 1.

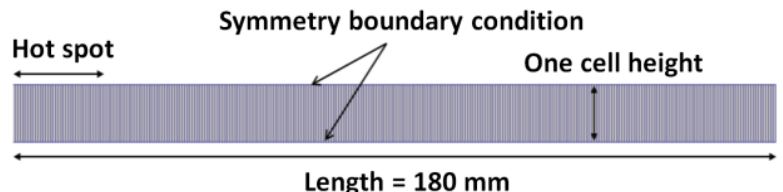

Figure 1: Calculation domain.

A grid convergence has been achieved using cells down to $6 \mu \mathrm{m}$ and the final mesh used for all calculations owns 3600 cells for a length of $180 \mathrm{~mm}$, which corresponds to cells of $50 \mu \mathrm{m}$.

To mimic the hot spot, a linear temperature gradient is initialized on the left part of the domain with a defined amplitude and radius. Figure 2 illustrates this simplified configuration. For this study, $T_{0}$ is chosen outside of the Negative Temperature Coefficient (NTC) region where $\tau_{i}$ increases as $T$ decreases.

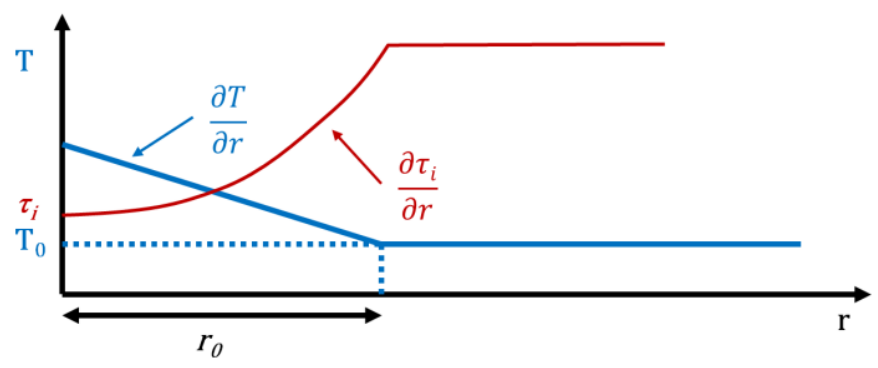

Figure 2: Initial hot spot definition.
A "symmetry" boundary condition is defined at the center of the hot spot (left part of the domain) and a constant pressure boundary condition is defined at the outlet.

Regarding initial conditions, the domain is fueled using an air-TRF mixture (RON95 surrogate with $42.8 \%$ isooctane, $13.7 \%$ n-heptane, $43.5 \%$ toluene). Different thermodynamic conditions in terms of pressure $P_{0}$ and temperature $T_{0}$ in the homogeneous part of the domain are analyzed to be as close as possible to real engine conditions. However, the NTC region that is usually obtained below $900 \mathrm{~K}$ is not investigated in this article as it needs the use of a "cold spot" and not a "hot spot", but will be part of future studies. Variations of equivalence ratio and EGR rate are also analyzed in the result part of the article (these two last parameters being considered in the framework of lean and diluted SI engines).

Involving a complex chemical mechanism in numerical codes to solve chemistry of realistic fuels requires computing thousands of species and reactions. This methodology is too CPU time consuming as the objective is to analyze a large number of operating conditions to precisely define the detonation peninsula. The tabulated model TKI-LES model [15-22] has thus been chosen to simulate autoignition as previous studies have already shown its ability to catch such phenomenon [23]. This model is based on a look-up table of $\tau_{i}$ and $\tau_{e}$, obtained using a priori calculations for the same surrogate fuel in homogeneous reactors and considering the LLNL kinetic mechanism with 1388 species and 5935 reactions [24]. The chemical computations are first performed with an in-house code named CLOE (based on the Senkin solver), and the resulting auto-ignition characteristic time scales $\left(\tau_{i}, \tau_{e}\right)$ are then tabulated for different pressure, temperature, EGR and equivalence ratio levels. The autoignition delay time $\tau_{i}$ is defined as the time needed to increase the mixture temperature by $400 \mathrm{~K}$ compared to the initial conditions. The excitation time $\tau_{e}$ is the time required for the heat release rate to rise from $5 \%$ to its maximal value. This characteristic time being of the order of $\mu \mathrm{s}$, a high temporal resolution is required for the postprocessing to guarantee accurate calculations. The values of $\tau_{i}$ and $\tau_{e}$ are just read in the table during the $1 \mathrm{D}$ calculations.

\section{Calculation hypothesis for $\varepsilon$ and $\xi$}

The reactivity and coupling parameters $(\varepsilon, \xi)$ are defined using the initial conditions of the domain. Referring to the original works of $\mathrm{Gu}$ and Bradley, the initial temperature at $r=r_{0} / 2$ is used to determine $\tau_{i}$ and $\tau_{e}$, then to calculate $\varepsilon$ and $\xi$. The choice of the reference temperature location has a significant impact on the calculation of $(\varepsilon$, $\xi)$ values. This topic has already been discussed in [15] but Figure 3 shows for other initial conditions, the variations of these parameters as a function of the temperature increase at the center of the hot spot $\Delta T_{0}$ for three hypotheses: when the reference temperature is taken at the outer limit of the hot spot (assumption $\mathrm{n}^{\circ} 1, r=r_{0}$ ), at the middle of the hot spot (assumption $\mathrm{n}^{\circ} 2, r=r_{0} / 2$ ), and at the center of the hot spot (assumption $\mathrm{n}^{\circ} 3, r=0$ ).

Page 3 of 8 

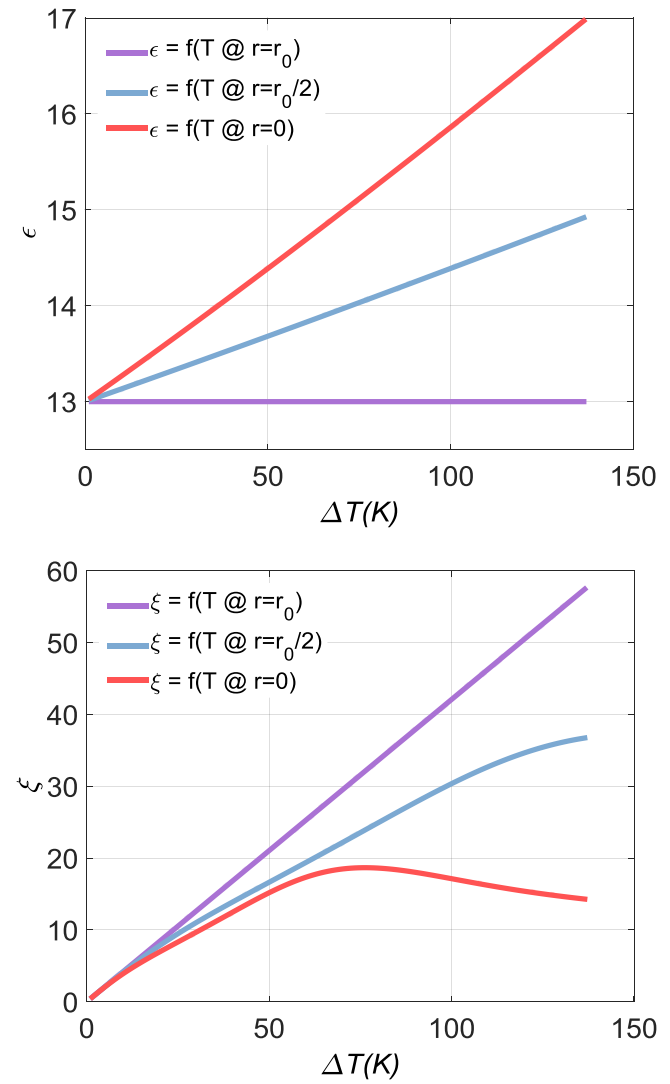

Figure 3: Impact of the reference temperature on $\varepsilon$ (top) and $\xi$ (bottom) values as a function of $\Delta T_{0}$ at the center of the hot spot $\left(r_{0}=29.6 \mathrm{~mm}, P_{0}=50 \mathrm{bar}\right.$, $T_{0}=900 \mathrm{~K}, \phi=1$, no dilution).

Even if thermal initial conditions are really different, conclusions are the same as in [15]. For the highest $\Delta T_{0}$, the estimation of the two parameters varies a lot, meaning that for the same initial conditions, the position on the detonation peninsula is totally different. Table 1 summarizes the $\varepsilon$ and $\xi$ values obtained by considering these three different assumptions for the same hot spot configuration $\left(r_{0}=29.6 \mathrm{~mm}\right.$ and $\left.\Delta T_{0}=100 \mathrm{~K}\right)$. The impact of the reference temperature on $\varepsilon$ is rather limited but the impact on $\xi$ values is really significant. Of course, only one single auto-ignition propagation mode (a subsonic deflagration) is obtained for this hot spot configuration as initial conditions are the same, but the chosen assumption has a large impact on peninsula limit position.

For the fuel sensitivity analysis conducted in this study, a proper comparison with the original detonation peninsula provided by $\mathrm{Gu}$ and Bradley can only be achieved if a similar assumption is made regarding the choice of the reference temperature. The estimation of $(\varepsilon, \xi)$ at $r=r_{0} / 2$ is used for the following cases.

Table 1: Impact of the reference temperature on $(\varepsilon, \xi)$ values for $\Delta T_{0}=100 \mathrm{~K}$ ( $r_{0}=29.6 \mathrm{~mm}, P_{0}=50 \mathrm{bar}, T_{0}=900 \mathrm{~K}, \phi=1$, no dilution).

\begin{tabular}{|l|c|c|}
\hline Assumption & $\varepsilon$ & $\xi$ \\
\hline 1: T @ $r=r_{0}$ & 13.0 & 17.6 \\
\hline 2: T @ $r=r_{0} / 2$ & 14.3 & 30.2 \\
\hline 3: T @ $r=0$ & 15.9 & 41.8 \\
\hline
\end{tabular}

Page 4 of 8
Figure 3 also shows that the variation of $\xi$ with $\Delta T_{0}$ is not monotonic. For the example considered, $\xi$ reaches a maximal value around 19 for $\Delta T_{0}$ close to $70 \mathrm{~K}$ and then slightly decreases. This particular behavior is observed with TRF-air mixtures because their critical temperature gradient is increasing (as $\Delta T_{0}$ increases) faster than the temperature gradient (Eq. 2) around the hot spot. This behavior is related to the specific auto-ignition delay variation as a function of the temperature for TRF-air mixtures and was not reported so far in the case of $\mathrm{H}_{2}-\mathrm{CO}$-air mixtures because the maximal $\xi$ value for these mixtures is much higher (around 100 for the same initial conditions as Figure 3 of [15]).

\section{Results}

\section{Auto-ignition mode classification}

Hundreds of calculations have been performed with multiple initial conditions regarding the hot spot and the surrounding mixture. An automatic post-processing procedure has been defined to quickly identify the auto-ignition propagation mode for each considered case. This post-processing procedure is based upon the analysis of the relative position and velocity of the reaction and pressure waves. The analysis is carried out at the moment when the reaction wave reaches $r=r_{0}$, just before the reaction begins its propagation into a perfectly homogeneous mixture.

Theoretically, the detonation mode is reached when the positions and speeds of the reaction and pressure fronts perfectly coincide. However, a tolerance of $10 \%$ is used here on speed and position in order to take into account transition phenomena during which pressure and reaction fronts chase each other. The criteria used to differentiate the main modes of propagation are summarized in Table 2 as a function of the reaction and pressure wave speeds and positions (respectively named $u_{a}, x_{a}, a, x_{p}$ ).

Table 2. Identification criteria for auto-ignition propagation modes.

\begin{tabular}{|l|c|c|}
\cline { 2 - 3 } \multicolumn{1}{c|}{} & $\begin{array}{c}\text { Reaction front speed } \\
u_{a}\end{array}$ & $\begin{array}{c}\text { Reaction front position } \\
x_{a}\end{array}$ \\
\hline Developing detonation & $0.9 * a<u_{a}<1.1 * a$ & $0.9 * x_{p}<x_{a}<1.1 * x_{p}$ \\
\hline Subsonic deflagration & $u_{a} \leq 0.9 * a$ & $x_{a} \leq 0.9 * x_{p}$ \\
\hline Supersonic deflagration & $u_{a} \geq 1.1 * a$ & $x_{a} \geq 1.1 * x_{p}$ \\
\hline
\end{tabular}

Thanks to these criteria, the automation of the data post-processing made possible to build several peninsulas for various conditions in terms of pressure, temperature, equivalence ratio and dilution rate. These new detonation peninsulas are presented in the next section.

\section{Detonation peninsulas}

Figures 4 to 6 show the three detonation peninsulas obtained for initial temperature $T_{0}$ varying between 900 and $1100 \mathrm{~K}$.

The maximal temperature at the center of the hot spot depends on its radius and temperature gradient. In order to analyze auto-ignition events occurring in realistic engine conditions, it is therefore necessary to confront the assumptions made for the hot spot with realistic mixture characteristics in engines and especially with the maximal fresh gases temperature. For this reason, the maximal temperature assumed at the center of the hot spot cannot exceed $1200 \mathrm{~K}$, which is already a very high temperature in engine operating 
conditions. For given hot spot radius $r_{0}$ and initial temperature $T_{0}$, the maximal temperature gradient around the hot spot is thus limited. Consequently, the maximal attainable $\xi$ value is also limited. This limitation is shown by the blue areas in Figures 4 to 6, pointing out that the area of the relevant domain depends on the level of temperature $T_{0}$. The higher $T_{0}$ is, the lower maximal value for $\xi$ are, because large hot spot radii with high temperature gradients (high values of $\xi$ ) would lead to non-realistic temperature at the center of the hot spot. It can also be noticed in Figure 6 that the upper limit of the new peninsula (red dotted line) is shortened at $\varepsilon \approx 10$ as it crosses the upper limit of the relevant engine region.

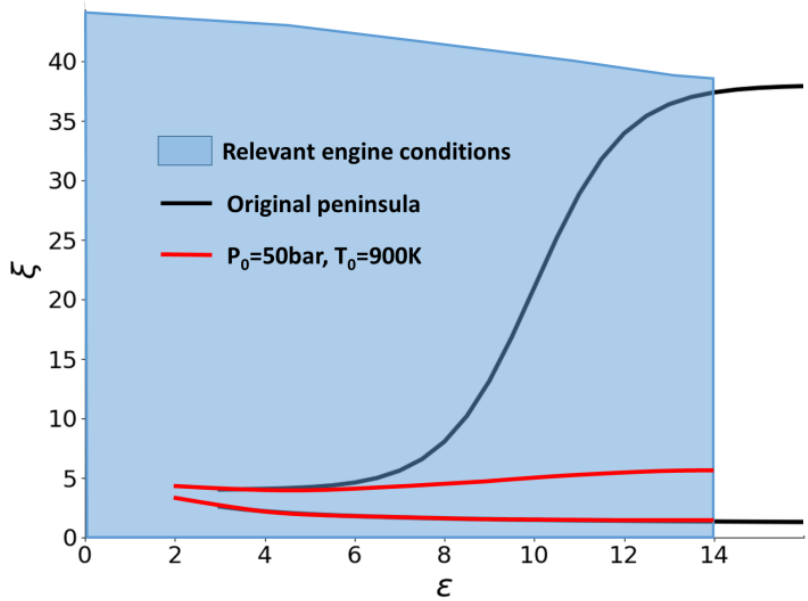

Figure 4: Computed detonation peninsula with $\mathrm{T}_{0}=900 \mathrm{~K}\left(P_{0}=50 \mathrm{bar}, \phi=1\right.$ and $\mathrm{EGR}=0 \%$ ).

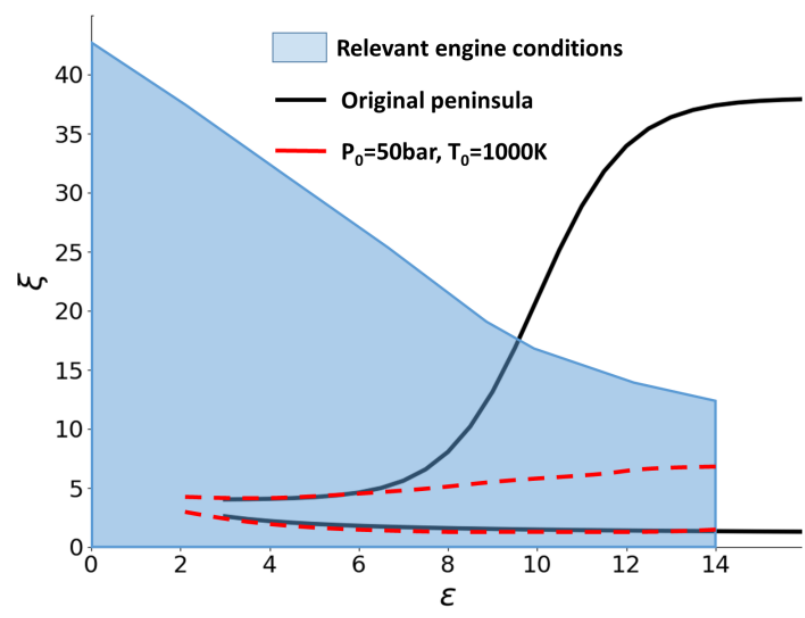

Figure 5: Computed detonation peninsula with $T_{0}=1000 \mathrm{~K}\left(P_{0}=50 \mathrm{bar}\right.$, $\phi=1$ and $\mathrm{EGR}=0 \%)$.

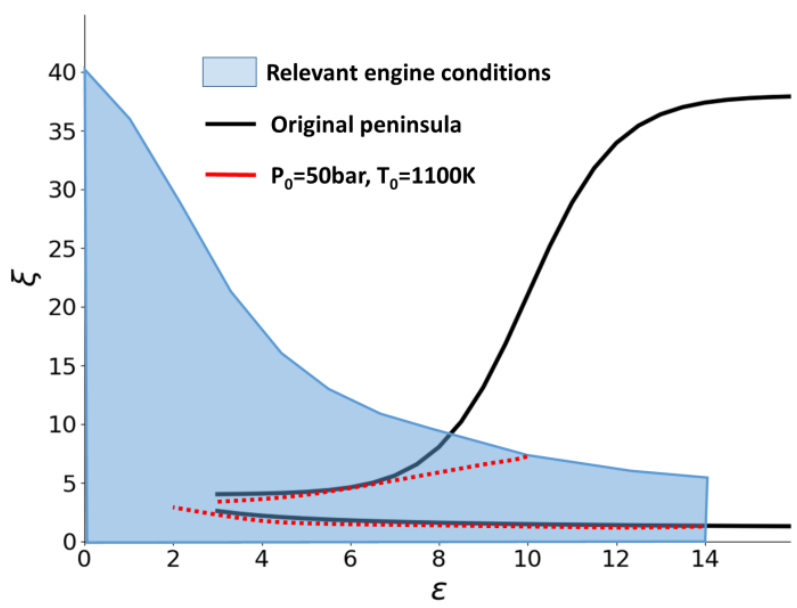

Figure 6: Computed detonation peninsula with $T_{0}=1100 \mathrm{~K}\left(P_{0}=50 \mathrm{bar}\right.$, $\phi=1$ and $\mathrm{EGR}=0 \%)$.

The hot spot radius has also been limited to a few millimeters in order to represent typical mixture heterogeneities in SI engines. However, in some specific cases (when auto-ignition occurs early during the cycle for example), the premixed flame front is still in the middle of the combustion chamber. The available fresh gases length is not the distance between flame front and the liner, but the circumference of the combustion chamber, allowing potentially larger hot spots. The authors considered thus that hot spot radius around $20 \mathrm{~mm}$ are still acceptable even if in a real engine, the probability to obtain in such huge hot spot radii is low.

Defining a maximal hot spot radius $r_{0}$ value directly implies a maximal value of the reactivity parameter for engine cases at a given pressure and temperature. Figure 7 shows the evolution of $r_{0}$ depending on parameter $\varepsilon$ for three initial temperatures $T_{0}$. When the temperature increases, excitation time decreases and based on Eq. 3, the $\varepsilon$ value increases if the sound speed variation is neglected. However, the initial temperature $T_{0}$ has a limited influence on the evolution of $r_{0}$ at a given $\varepsilon$ value. If realistic hot spot radii (lower than $20 \mathrm{~mm}$ ) are considered, region where $\varepsilon$ is higher than 10 should not be reached when analyzing auto-ignition events in SI engines. In order to extend the analysis, values of $\varepsilon$ until 14 are studied in this paper, upper limit which is still lower than the original peninsula one.

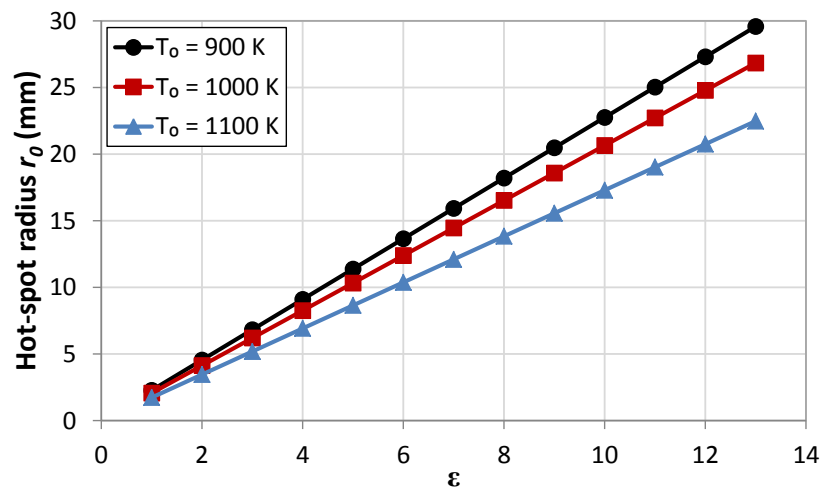

Figure 7: Evolution of the hot spot radius $r_{0}$ as a function of $\varepsilon$ for three different initial temperatures $T_{0}\left(P_{0}=50\right.$ bar, $\phi=1$ and EGR $\left.=0 \%\right)$.

Focusing now on the new detonation peninsula locations predicted by numerical calculations (red lines), results from Figures 4 to 6 are 
presented on the same graph in Figure 8 (using a logarithmic scale for the $\xi$ axis to improve readability). Whatever the initial temperature chosen, new detonation peninsulas have a close location. However, the upper limit of the detonation peninsula estimated in this study is lower than the original one for values of the reactivity parameter $\varepsilon$ between 8 and 14, reducing the region where detonation can occur.

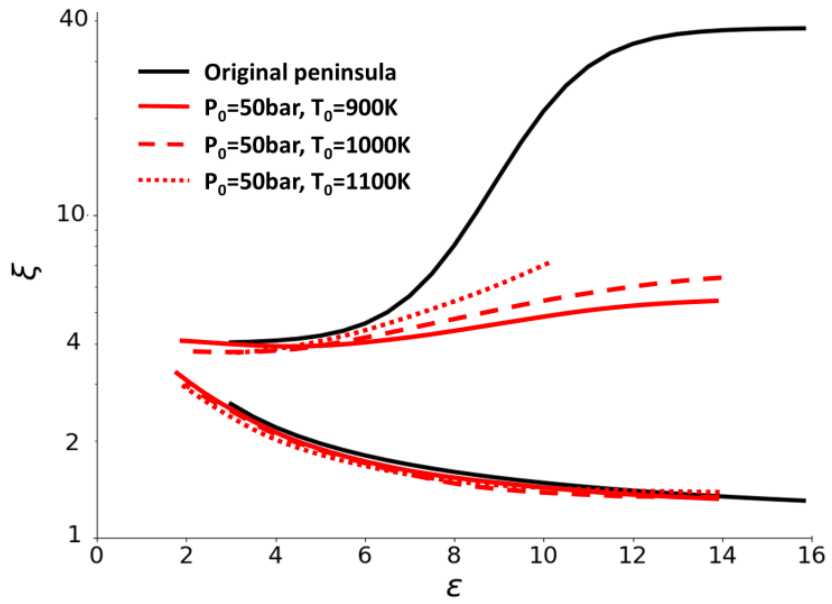

Figure 8: Computed detonation peninsulas with $P_{0}=50$ bar, $\phi=1, \mathrm{EGR}=0 \%$ and for three initial temperatures $T_{0}$.

A variation of the pressure $P_{0}$ is also achieved with initial levels of 40, 50 and 70 bar. The resulting detonation peninsulas are presented in Figure 9 (red lines) in comparison to the original one. The relevant engine domain is not presented here but is quite similar to the one shown in Figure 5 as it depends little on the initial value of $P_{0}$. The evolution of the hot spot radius over $\varepsilon$ is also not presented here as the impact of $\mathrm{P}_{0}$ is still much more limited than the influence of $T_{0}$. Looking at the position of the three new peninsulas, the small difference induced by the pressure change can be neglected. A slight vertical shift is observed but clear borders are impossible to establish precisely (as a reminder, arbitrary margins of $10 \%$ are used to detect detonation), that is why new detonation peninsulas are considered to be consistent with the original peninsula except for the upper limit where $\varepsilon$ is greater than 8 ). As for the $T_{0}$ variation, the predicted peninsulas are much thinner, reducing thus a lot the probability to observe a developing detonation.

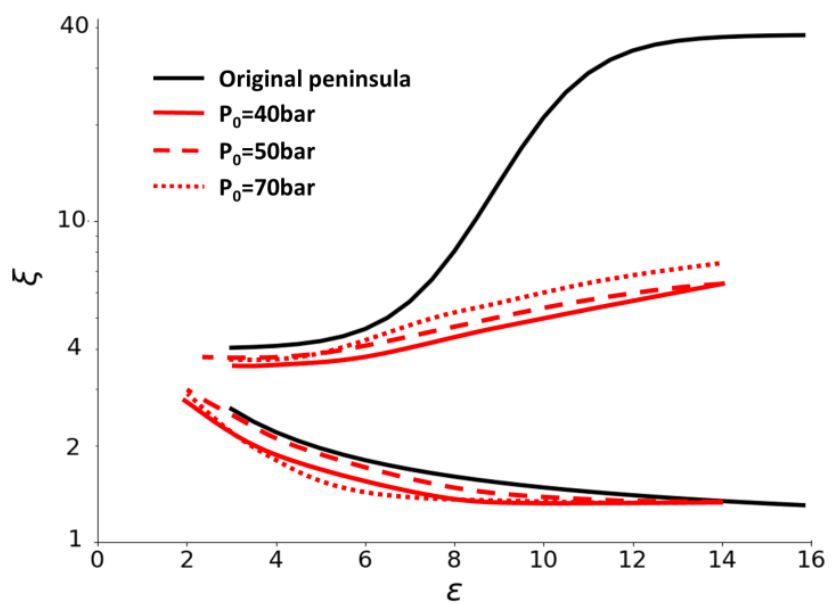

Figure 9: Computed detonation peninsulas with $P_{0}$ between $40-70$ bar $\left(T_{0}=1000 \mathrm{~K}, \phi=1\right.$ and $\left.\mathrm{EGR}=0 \%\right)$.

Page 6 of 8
The variation of initial equivalence ratio (see Figure 10) points out that the upper limit of the new peninsulas is moving down as the equivalence ratio is increasing. This evolution is limited but the overall surfaces of the new peninsulas are lower than the original one for values of $\varepsilon$ higher than 8 , as for the two previous parametric variations.

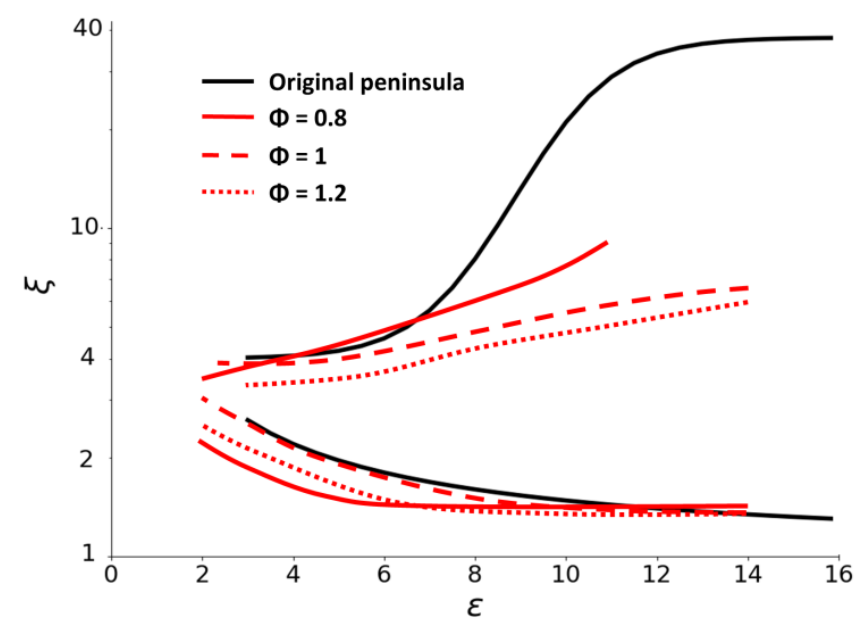

Figure 10: Computed detonation peninsulas with $\phi$ varying between 0.8 and $1.2\left(P_{0}=50\right.$ bar, $T_{0}=1000 \mathrm{~K}$ and $\left.\mathrm{EGR}=0 \%\right)$.

Figure 11 shows that much higher hot spot radii are required with lean mixtures to reach similar reactivity parameter $\varepsilon$ as for stoichiometric mixtures. Indeed, when the fuel-air equivalence ratio is decreased, the excitation times are also significantly decreased which explains that the reactivity parameter is lower in lean conditions than in stoichiometric conditions for a given hot spot radius. It must be noted, however, that these fuel-air equivalence ratio variation has been performed with constant pressure and temperature which would not be possible in an engine.

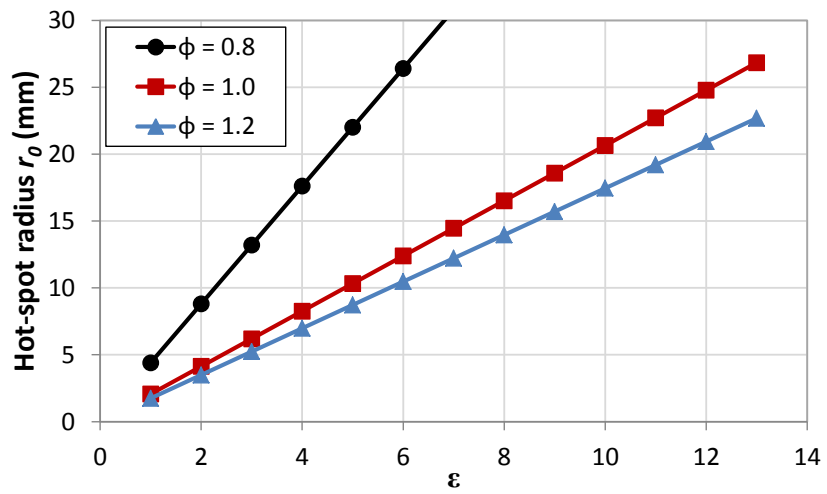

Figure 11: Evolution of the hot spot radius $r_{0}$ as a function of $\varepsilon$ for three different initial equivalence ratios $\left(P_{0}=50 \mathrm{bar}, T_{0}=1000 \mathrm{~K}\right.$ and $\left.\mathrm{EGR}=0 \%\right)$.

The last parametric variation of the initial conditions is the dilution rate. In this study, the real composition of exhaust gases is not considered and the dilution is performed with pure nitrogen only (called EGR in the following figures). The dilution rate was varied between 10 and $30 \%$ in volume. It is important to notice that the initial temperature $T_{0}$ is kept constant to $1000 \mathrm{~K}$ for these investigations, whereas the main objective of dilutant addition at high load in SI engines is to reduce end gases temperature. 
Figure 12 points out the large effect of the dilution rate on the calculation of the reactivity parameter $\varepsilon$ at a given hot spot radius $r_{0}$. Indeed, the excitation time sharply increases when dilution rate increases, which reduces the maximal attainable value of $\varepsilon$ to keep initial radius $r_{0}$ consistent with mixture heterogeneities length scale in SI engines. In others words, for high dilution rates, the developing detonation peninsula is very thin and should be limited to a maximum value of $\varepsilon=2$.

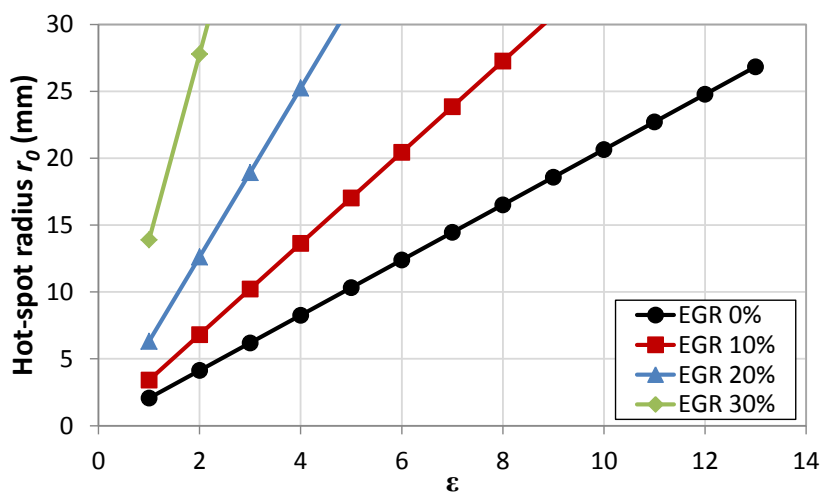

Figure 12: Evolution of the hot spot radius $r_{0}$ as a function of $\varepsilon$ for four different initial dilution rates $\left(P_{0}=50 \mathrm{bar}, T_{0}=1000 \mathrm{~K}\right.$, and $\left.\phi=1\right)$.

However, the new peninsulas presented in Figure 13 do not take into account this aspect in order to provide a fuller comparison of the considered configurations. For this new variation, the impact is much more visible: the detonation peninsula clearly moves from right to left and the upper limit of the detonation peninsula is much steeper when dilution rate increases.

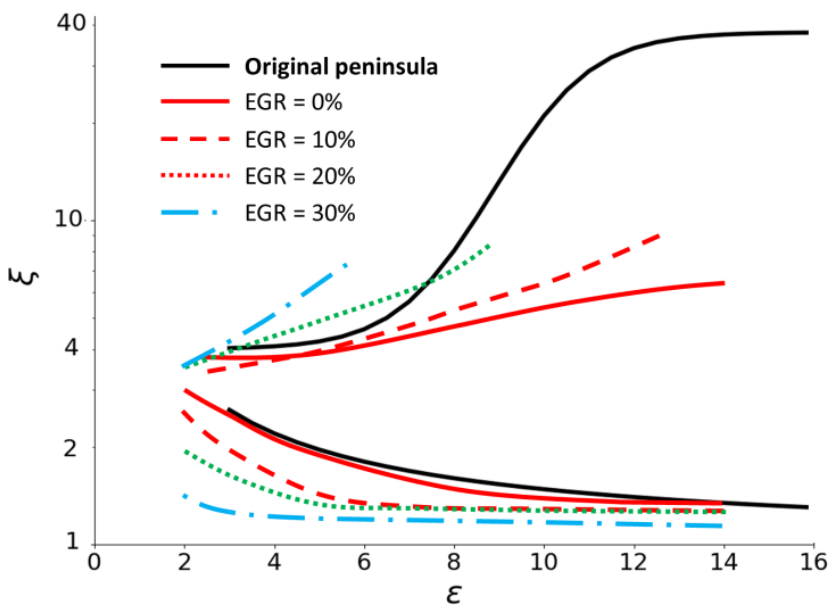

Figure 13: Computed detonation peninsulas with EGR rates varying between 0 and $30 \%\left(P_{0}=50 \mathrm{bar}, T_{0}=1000 \mathrm{~K}\right.$ and $\left.\phi=1\right)$. A logarithmic scale is used for $\xi$.

\section{Summary}

The location of the detonation peninsula has been studied as a function of the hot spot characteristics, and as a function of four parameters characterizing the surrounding mixture: the initial temperature and pressure, the fuel-air equivalence ratio and the dilution rate.
In all cases, the new detonation peninsulas obtained for TRF-air mixtures are much thinner than the original one defined for $\mathrm{H}_{2}-\mathrm{CO}$ air mixtures, especially for $\varepsilon$ values higher than 8 .

On one hand, the initial temperature and pressure $\left(T_{0}\right.$ and $\left.P_{0}\right)$ around the hot spot only have a very limited impact on the upper and lower limits of the detonation peninsula.

On the other hand, the fuel-air equivalence ratio and the dilution rate have a much stronger effect on the detonation peninsula, and particularly on the position of its upper limit. Diluting the mixture with air or with EGR leads to significant increases in excitation times $\tau_{e}$, and consequently only very low $\varepsilon$ values can be reached with realistic hot spot radii. Besides, the upper limit of the detonation peninsula is getting steeper and steeper at low $\varepsilon$ values when the dilution rate increases.

\section{Conclusions}

This article aims at verifying the developing detonation peninsula location for a TRF fuel compared to the original one proposed by Bradley and his coworkers for $\mathrm{H}_{2}-\mathrm{CO}$.

1D calculations have been performed for various $(\varepsilon, \xi)$ values corresponding to real engine operating conditions. This analysis is based on the assumption that hot spots in real engine conditions cannot exceed around $20 \mathrm{~mm}$ of radius, and that their maximal temperature is lower than $1200 \mathrm{~K}$. It is also important to keep in mind that the resulting locations for detonation peninsulas depends on the used classification criteria, chosen here at $r=r_{0} / 2$. It follows a possible SI engine zone located between 0 and 10 for the reactivity parameter $\varepsilon$ (extended to 14 in this study) and between 0 and 45 for coupling parameter $\xi$.

An automatic post-processing method has been developed and validated to analyze the hundreds of $1 \mathrm{D}$ calculations needed for each peninsulas. This methodology makes possible the achievement of variations of initial pressure, temperature, fuel-air equivalence ratio or dilution rate.

The analysis of detonation peninsulas points out that the location of the developing detonation zone is independent of the initial pressure or temperature level. Its location is more affected by the increase of the equivalence ratio (which tends to make thinner the developing detonation zone) and much more by the dilution rate which is responsible for an increase of the area of the detonation peninsula at low $\varepsilon$ values. Finally, based on all the studied cases, it can be stated that the original detonation peninsula obtained for $\mathrm{H}_{2}-\mathrm{CO}$ mixture is also valid for TRF fuel at $\varepsilon$ values lower than 8 , but overestimates the developing detonation region for $\varepsilon$ between 8 and 14 .

The use of the detonation peninsula to analyze auto-ignition intensity is not limited to abnormal combustion. This tool can also be used to better understand advanced combustion concepts such as Spark Assisted Compression Ignition (SACI) for which auto-ignition must be controlled, but not avoided, to increase the efficiency without damaging the engine. Indeed, the evolution of $\varepsilon$ points out that the lean mixture and dilution rate up to $30 \%$ reduces the detonation peninsula to a very thin zone. An easier control of SACI combustions seem to be directly linked to longer fuel excitation time, combined with the use a lean or diluted mixture. 
In future works, the choice of initial temperature $T_{0}$ in the NTC region, using "cold spots" will be investigated to complement this study. The influence of dilution rate at lower initial temperatures has also to be analyzed, as one of the more important effect of dilution is the cooling of fresh gases. The next step will then be to combine these new detonation peninsulas obtained with diluted TRF-air mixtures with 3D calculations in order to maximize the controllable auto-ignition fraction during combustion and thus the efficiency.

\section{References}

1. Clerk, D., Transactions of the Faraday Society 22 (1926), 338340.

2. Zeldovich, Y.B., Combust. Flame 39 (1980) 211-214.

3. Goyal, G., Maas, U., Warnatz, J., SAE Technical Paper 900026, 1990.

4. Goyal, G., Warnatz, J., Maas, U., Proc. Combust. Inst., 23 (1991) 1767-1773.

5. König, G., Maly, R., Bradley, D., Lau, A., Sheppard, C., SAE Technical Paper 902136, 1990.

6. Bradley, D., Morley, C., Emerson, D.R., SAE Technical Paper 2002-01-2868, 2002.

7. Bradley, D., Morley, C., Walmsley, H. L., SAE Technical Paper 2004-01-1970, 2004.

8. Kalghatgi, G.T., Bradley, D., Int. J. Engine Res. 13 (2012), 399414.

9. Rudloff, J., Zaccardi, J-M., Richard, S., Anderlohr, J.M., Proc. Combust. Inst. 34 (2013) 2959-2967.

10. Robert, A., Richard, S., Colin, O., Poinsot, T., Comb. and Flame 162 (2015) 2788-2807.

11. Misdariis, A., Vermorel, O., Poinsot, T., Proc. Combust. Inst. 35 (2015) 3001-3008.

12. Bates, L., Bradley, D., Paczko, G., Peters, N., Comb. and Flame 166 (2016), 80-85.

13. Gu, X.J., Emerson, D.R., Bradley, D., Combust. Flame 133 (2003) 63-74.

14. Dai, P., Chen, Z., Chen, S., Ju, Y., Proc. Combust. Inst. 35 (2015) 3045-3052

15. Robert A., Zaccardi J-M, Dul C., Guerouani A., Rudloff J., Int. J. Engine Res., (2018), published on-line.

16. Zeldovich, Y.B., Librovich, V.B., Makhviladze, G.M., Sivashinsky, G.I., Astronaut. Acta 15 (1970) 313-321.

17. Peters N, Kerschgens B, Jochim B and Paczko G. Proc. of the 4th Int. Conf. on knocking in gasoline engines, (2013) Berlin

18. Tanoue et al., Int. J. Engine Res., 17 (2016) , 666-676

19. Netzer, C., Seidel, L., Pasternak, et al., SAE Technical Paper, 2017-01-0538, 2017.

20. Bates, L. and Bradley, D, Combust. Flame 175 (2017) 118-122

21. Gourdain, N., Gicquel, L., Staffelbach, G., Vermorel, O., Duchaine, F., Boussuge, J.-F., Poinsot, T., Comput. Sci. Discovery 2(1) (2009) 015004.

22. Colin, O., Da Cruz, A. P., Jay, S., Proc. Combust. Inst. 30 (2005), 2649-2656.

23. Robert, A., Richard, S., Colin, O., Martinez, L., De Francqueville, L., Proc. Combust. Inst. 35 (2015), 2941-2948.

24. Mehl, M., Pitz, W. J., Westbrook, C. K. and Curran, H. J., Proc. Combust. Inst. 33 (1) (2011) 193-200.

\section{Contact Information}

Dr. Anthony ROBERT, anthony.robert@ifpen.fr

Dr. Jean-Marc ZACCARDI, j-marc.zaccardi@ifpen.fr

IFP Energies nouvelles, Institut Carnot IFPEN TE., 1-4 Avenue du Bois Préau, 92852 Rueil-Malmaison, France

\section{Definitions/Abbreviations}

$\tau_{i}$

$\tau_{e}$

$\varepsilon$

$\xi$

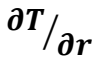

$(\partial T / \partial r)_{c}$

$a$

$r_{0}$

$\Delta \mathbf{T}_{\mathbf{0}}$

$\mathbf{P}_{0}$

$\mathbf{T}_{\mathbf{0}}$

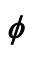

$\boldsymbol{u}_{\boldsymbol{a}}$

$x_{a}$

$x_{p}$
Auto-ignition delay time

Excitation time

Hot spot reactivity

Coupling parameter

Hot spot temperature gradient

Critical hot spot temperature gradient

Acoustic speed

Initial hot spot radius

Temperature increase at the hot spot

Initial pressure outside the hot spot

Initial temperature outside the hot spot

Fuel-air equivalence ratio

Reaction wave speed

Reaction wave position

Pressure wave position 